\title{
INCIDÊNCIA DE INFECÇÕES DA CORRENTE SANGUÍNEA EM PACIENTES NEFROPATAS
}

\author{
INCIDENCE OF BLOODSTREAM INFECTIONS IN PATIENTS WITH KIDNEY DISEASE
}

\section{Patrícia Alves Paiva ${ }^{a}$, Bruno Pereira de Paulab, Maria de Fátima Fernandes Santosc, Beatriz Rezende Marinho da Silveira ${ }^{\mathrm{d}}$}

apatricia.alves.paiva@hotmail.com, bbrunoppaula2009@yahoo.com.br, cmariadefatimafernandessantos@gmail.com, dvalicol@hotmail.com Universidade Estadual de Montes Claros - Montes Claros (MG), Brasil

\section{RESUMO}

Objetivo: Identificar a incidência de infecçôes da corrente sanguínea em pacientes portadores de insuficiência renal crônica em tratamento hemodialítico e traçar o perfil dos agentes etiológicos encontrados com maior frequência nas hemoculturas realizadas para diagnóstico quanto à sensibilidade ao antimicrobiano. Metodologia: Trata-se de um estudo quantitativo, documental, descritivo, exploratório e do tipo transversal, desenvolvido em um serviço de referência em nefrologia no município de Montes Claros, Minas Gerais. As informaçôes foram coletadas entre agosto e dezembro de 2013, por meio de documentos institucionais, tais como livros de ocorrências, prontuários de pacientes e resultados de exames microbiológicos de hemoculturas. Para avaliar o perfil de sensibilidade das bactérias isoladas nas hemoculturas, utilizou-se o protocolo do Serviço de Controle de Infecção Hospitalar do hospital em estudo. Resultados: Durante o período foram incluídos na pesquisa 100 pacientes que realizaram hemocultura, sendo que $60 \%$ eram do sexo masculino e $40 \%$ do sexo feminino. Do total, $54,5 \%$ dos pacientes tinham idade superior a 60 anos. Foram analisadas 152 hemoculturas, das quais 74 deram positivas $(58,9 \%)$. A bactéria mais predominante nas infecçóes da corrente sanguínea foi o Staphylococcus aureus $(57,6 \%)$. Conclusão: Pode-se concluir que a incidência de infecção por bactérias multirresistentes é alta e tem como destaque o Staphylococcus aureus. O isolamento destas bactérias multirresistentes é preocupante, haja vista as limitaçôes de opçóes terapêuticas e o aumento da letalidade.

Palavras-chave: Infecção hospitalar; insuficiência renal crônica; diálise renal.

\section{ABSTRACT}

Objective: To identify the incidence of bloodstream infections in patients with chronic renal insufficiency on hemodialysis and to identify the profile of the most frequently found etiological agents in blood cultures performed for diagnosis of antimicrobial susceptibility. Methodology: This is a quantitative, documental, descriptive, exploratory and cross-sectional study, developed at a referral service in nephrology in the municipality of Montes Claros, Minas Gerais, Brazil. The information was collected between August and December 2013, through institutional documents, such as case histories, patients' records and results of microbiological examinations of blood cultures. To evaluate the sensitivity profile of the bacteria isolated in the blood cultures, a protocol from the Infection Control Service of the hospital under study was used. Results: During the period 100 patients who underwent blood culture were included, $60 \%$ of whom was male and $40 \%$ was female. A total of $54.5 \%$ of the patients were older than 60 years. A total of 152 blood cultures was analyzed, of which 74 were positive (58.9\%). The most prevalent bacteria in the bloodstream infections was Staphylococcus aureus (57.6\%). Conclusion: It can be concluded that the incidence of infection by multiresistant bacteria is high and the Staphylococcus aureus stands out. The isolation of these multiresistant bacteria is worrying, due to the limitations of therapeutic options and the increasing lethality.

Keywords: Cross infection; chronic renal insufficiency; renal dialysis. 


\section{Introdução}

A doença renal crônica (DRC) é um problema de saúde pública que tem aumentado de forma significativa sua prevalência e incidência em países com diversas características econômicas ${ }^{1}$. É uma doença lenta e silenciosa que provoca perda total das funçóes renal, tais como de regulação, de excreção e endócrina, levando à adoção de terapias renais substitutivas, como a hemodiálise. Ao se deparar com essa necessidade o paciente passa por um processo de rejeição e de aceitação, que interfere no seu estado emocional e psicológico, gerando algumas consequências na forma de enfrentar a doença e o tratamento ${ }^{2}$.

A hemodiálise é um procedimento que filtra, limpa, purifica o sangue e ajuda a manter o equilíbrio de substâncias químicas corporais por meio de circulação sanguínea extracorpórea, através de um acesso vascular. É um tratamento indispensável para a manutenção da vida, mas que é visto como doloroso, monótono e limitado ${ }^{3}$. No Brasil, foram realizados 91.475 procedimentos de hemodiálise no ano de 2008, em 2012, 118.847. Para o ano 2017, estimou-se um aumento de $24,8 \%$ na realizaçáo desse procedimento ${ }^{4}$. Para realização da hemodiálise, faz-se necessário a punção de um acesso venoso calibroso, que pode ser uma fístula arteriovenosa capaz de efetivar a terapia renal substitutiva ${ }^{5}$ Nesse contexto, há o risco de infecçóes relacionadas ao cateter venoso central para hemodiálise, o que oferece alto risco de agravos à saúde ${ }^{6}$, principalmente no que diz respeito à infecção da corrente sanguínea.

As infecçóes primárias da corrente sanguínea (IPCS) estão entre as mais comuns infecçôes hospitalares. No Brasil, são registrados $40 \%$ de mortalidade entre pacientes com infecção da corrente sanguínea. A Agência Nacional de Vigilância Sanitária (Anvisa) considera como IPCS associada à cateter central a infecção laboratorialmente confirmada em pacientes que usam esse tipo de sistema intravascu$\operatorname{lar}^{7}$, conceito utilizado neste estudo.

Quando se trata de pacientes com Insuficiência Renal Crônica Terminal (IRCT), a infecção de corrente sanguínea é a segunda causa de mortalidade, representando aproximadamente $14 \%$ dos óbitos, precedida somente por distúrbios cardiovasculares. Esse fato pode estar relacionado ao efeito imunossupressor que acometem os pacientes com insuficiência renal crônica, alimentação inadequada e necessidade de manutenção de acesso vascular por longos períodos. O controle desses riscos pode reduzir em cerca de $40 \%$ a incidência dessas infecções ${ }^{8,9}$.
Os sinais e sintomas mais comuns de infecção de corrente sanguínea são calafrios, febre, tremores, hipotensão, hiperemia ou exsudato no local de inserção do cateter. No entanto, a simples observação dessa sintomatologia náo sugere o agente causal. Por isso, faz-se necessário o isolamento do microrganismo por meio de hemocultura e cultura de ponta de cateter. A identificação do agente etiológico e a determinaçáo do seu perfil de sensibilidade antimicrobiana são importantes passos para um tratamento mais direcionado e boa evolução do paciente ${ }^{10}$.

As precauções padrão consistem na estratégia primária de prevenção da transmissão de infecções relacionadas à assistência à saúde entre pacientes e profissionais, e devem ser utilizadas nos cuidados prestados aos pacientes: higiene das mãos antes e após o contato; utilização de luvas, máscaras, óculos de proteção e aventais quando houver risco de contato com material biológico; cuidados com perfurocortantes; limpeza ambiental; processamento adequado de materiais e equipamentos e imunização dos profissionais de saúde ${ }^{8}$.

Baseado no exposto, este estudo teve como objetivo identificar a incidência de infecçóes da corrente sanguínea em pacientes portadores de insuficiência renal crônica em tratamento hemodialítico e traçar o perfil dos agentes etiológicos encontradas com maior frequência nas hemoculturas realizadas para diagnóstico quanto à sensibilidade ao antimicrobiano.

\section{Metodologia}

Trata-se de um estudo quantitativo, documental, descritivo, exploratório e do tipo transversal, desenvolvido em um serviço de referência em nefrologia no município de Montes Claros, Minas Gerais. A amostra foi do tipo não probabilística, pela qual se investigou dados de todos os pacientes atendidos pelo serviço de nefrologia que atendiam aos seguintes critérios de inclusão: serem portadores de Insuficiência Renal Crônica (IRC); estarem submetidos ao tratamento de hemodiálise; terem desenvolvido infecção da corrente sanguínea comprovada por realização de hemocultura no período de janeiro de 2012 a dezembro de 2013. Como critérios de exclusão, optou-se por considerar os resultados ilegíveis ou incompletos ou que não fossem comprovados por hemoculturas laboratoriais positivas.

O instrumento de coleta de dados utilizado para realizaçáo deste estudo foi composto por duas partes: a primeira se refere aos dados de caracterização dos 
pacientes, com as variáveis: sexo, idade, procedência e diagnóstico médico (de acordo com a Classificação Internacional das Doenças - CID 10). A segunda parte foi composta pelos resultados das hemoculturas, microrganismos identificados, perfil de sensibilidade e resistência bacteriana.

As informaçóes foram coletadas entre agosto e dezembro de 2013 pelos próprios pesquisadores deste estudo por meio de documentos institucionais, tais como livros de ocorrências, prontuários dos pacientes e resultados de exames microbiológicos das hemoculturas.

Os dados foram organizados em planilha eletrônica no software Microsoft Office Excel 2013 e analisados pela estatística descritiva, e os resultados foram apresentados em forma de tabelas, com frequência simples e com percentual das variáveis categorizadas.

Para análise da taxa de infecção hospitalar, utilizou-se como numerador a quantidade de casos novos de infecção hospitalar no período de estudo, e como denominador, o total de saídas (altas, óbitos e transferências) ou entradas no mesmo período. O coeficiente de sensibilidade aos antimicrobianos foi calculado tendo como numerador a quantidade de cepas bacterianas de um determinado microrganismo sensível a determinado antimicrobiano, e como denominador, o número total de cepas testadas no mesmo agente, com antibiograma realizado a partir dos espécimes encontrados.

Para avaliar o perfil de sensibilidade das bactérias isoladas nas hemoculturas, utilizou-se o protocolo do Serviço de Controle de Infecção Hospitalar (SCIH) do hospital em estudo, o qual define como bactérias multirresistentes: os Staphylococcus aureus resistentes à oxacilina e/ou com resistência intermediária ou completa à vancomicina; os Streptococcus pneumoniae com resistência completa ou intermediária à penicilina; os Estafilococo coagulase-negativo com resistência intermediária ou completa à vancomicina; e os Enterococus faecalis e faecium com resistência total ou intermediária à vancomicina.

Entre as bactérias gram-negativas não fermentadoras, considerou-se a Pseudomonas aeruginosa e o Acinetobacter spp. com resistência completa ou intermediária ao imipenem e/ou meropenem. Culturas positivas para Burkolderia cepacia são consideradas multirresistentes independentemente do perfil. Também preenchem os critérios de multirresistência, os Stenotrophomonas maltophilia resistentes ao trimetoprim-sulfametoxazol.

Quanto às enterobácterias (E. coli, Klebsiela, Proteus, Serratia, Enterobacter, Morganella, Providencia) produtoras de betalactamases de espectro expandido (ESBL), considerou-se como multirresistentes aquelas resistentes a dois antimicrobianos dos grupos de aminoglicosídeos (gentamicina e amicacina) e/ou cefalosporina de terceira e ou quarta geração (ceftazidina, ceftriaxona, cefepime) e com resistência completa ou intermediária ao ertapenem e/ou imipenem ou meropenem.

O estudo seguiu os princípios da Resolução n. 466/2012 do Conselho Nacional de Saúde do Ministério da Saúde. O projeto foi encaminhado ao Comitê de Ética e Pesquisa da Universidade Estadual de Montes Claros e obteve parecer favorável sob o número 311.738 .

\section{Resultados}

A amostra do estudo foi composta por $100 \mathrm{pa}$ cientes que atendiam aos critérios de inclusão. Estes haviam realizado um total de 152 hemoculturas, dentre as quais, após análise, 58,9\% (74) se mostraram positivas. Dos 100 pacientes acompanhados, 55 apresentaram infecção de corrente sanguínea, sendo que alguns pacientes foram acometidos mais de uma vez durante o período estudado, e 19 pacientes apresentaram apenas colonização por microrganismos.

Dos 55 pacientes que apresentaram IPCS, 60\% eram do sexo masculino e $40 \%$ do sexo feminino. Um total de $85,4 \%$ tinha idade acima de 41 anos, sendo que $54,5 \%$ apresentavam mais de 60 anos. Em relação ao diagnóstico de base nos pacientes com IPCS, as doenças mais frequentes foram Diabetes Mellitus (32,7\%) e Hipertensão Arterial Sistêmica $(7,3 \%)$, seguidas de lúpus eritematoso sistêmico $(1,8 \%)$ e doença renal policística $(1,8 \%)$, os demais casos $(56,4 \%)$ se incluem na categoria "sem informação", um número muito alto, limitando uma análise mais detalhada do perfil dos pacientes com infecção de corrente sanguínea.

Em relação à procedência, $63,7 \%$ dos pacientes eram da cidade de Montes Claros; 30,9\% eram de outras cidades da região; e $5,4 \%$ não informaram. A maioria dos pacientes $(67,3 \%)$ era procedente da zona urbana. Durante o período de janeiro de 2012 a dezembro de 2013, a taxa média de infecção relacionada à corrente sanguínea foi de 2,9\%, em 2012, e 2,0\%, em 2013. A Tabela 1 apresenta a incidência das infecçóes da corrente sanguínea dos pacientes submetidos à hemodiálise e diálise peritoneal no período estudado (2012 a 2013). Observa-se que a incidência das infecções do ano de 2013, em comparação com 2012, reduziu em 0,9\%. 
Tabela 1: Incidência de infecção primária da corrente sanguínea em pacientes submetidos à hemodiálise e diálise peritoneal em serviço de referência nos anos de 2012 e 2013.

\begin{tabular}{lcc}
\hline Mês & Taxa de IPCS 2012 & Taxa de IPCS 2013 \\
\hline Janeiro & 1,6 & 2,4 \\
\hline Fevereiro & 3,3 & 1,6 \\
\hline Março & 4,9 & 0,8 \\
\hline Abril & 2,4 & 3,1 \\
\hline Maio & 1,7 & 1,5 \\
\hline Junho & 2,6 & 1,6 \\
\hline Julho & 0,8 & 2,3 \\
\hline Agosto & 1,6 & - \\
\hline Setembro & 5,3 & 3,0 \\
\hline Outubro & 0,8 & 3,5 \\
\hline Novembro & 3,3 & 1,4 \\
\hline Dezembro & 6,5 & 2,9 \\
\hline Média anual & 2,9 & 2,0 \\
\hline
\end{tabular}

Fonte: Elaborada pelos autores, 2014.

Os microrganismos identificados nas hemoculturas dos pacientes com IPCS durante o período de estudo estão listados conforme frequência simples e porcentagem na Tabela 2. A proporção de bacilos gram-negativos foi maior que a dos gram-positivos $(55,4 \%$ e $44,6 \%$ respectivamente). Isoladamente, o Staphylococcus aureus foi o microrganismo mais encontrado na hemocultura $(57,6 \%)$.

Tabela 2: Distribuição de microrganismos causadores das infecções da corrente sanguínea em pacientes renais crônicos, segundo isolamento em hemocultura em serviço de referência nos anos de 2012 e 2013.

\begin{tabular}{lc} 
Microrganismos & Hemoculturas positivas - n. (\%) \\
Cocos gram-positivos & $\mathbf{3 3}(\mathbf{4 4 , 6 )}$ \\
\hline Staphylococcus aureus & $19(57,6)$ \\
\hline Staphylococcus epidermidis & $1(3,0)$ \\
Staphylococcus sp & $8(24,3)$
\end{tabular}

continua..
Tabela 2: Continuação.

\begin{tabular}{lc} 
Microrganismos & Hemoculturas positivas - n. (\%) \\
\hline Enterococcus & $2(6,1)$ \\
\hline Streptococcus do grupo 'viridans' & $1(3,0)$ \\
\hline Streptococcus agalactiae & $1(3,0)$ \\
\hline Streptococcus sp & $1(3,0)$ \\
\hline Bacilos gram-negativos & $41(55,4)$ \\
\hline Escherichia coli & $6(14,7)$ \\
\hline Citrobacter freundii & $1(2,4)$ \\
\hline Pseudomonas aeruginosa & $6(14,7)$ \\
\hline Pseudomonas sp & $2(4,9)$ \\
\hline Acinetobacter & $9(22,0)$ \\
\hline Stenotrophomonas maltophilia & $8(19,5)$ \\
\hline Enterobacter cloacae & $5(12,1)$ \\
\hline Morganella morganni & $1(2,4)$ \\
\hline Bacillus sp & $74(100)$ \\
\hline
\end{tabular}

Fonte: Elaborada pelos autores, 2014.

Baseadas no protocolo de classificação de multirresistência implantado no hospital de estudo pelo Serviço de Controle de Infecção Hospitalar, as Tabelas 3 e 4 apresentam, respectivamente, os perfis de resistência dos bacilos gram-positivos e gram-negativos no teste de sensibilidade aos antimicrobianos. Entre os 19 (57,6\%) isolados de Staphylococcus aureus obtidos em hemocultura, $1(5,2 \%)$ foi resistente à oxacilina. Entre os $8(19,5 \%)$ isolados de Stenotrophomonas maltophilia, 3 (37,5\%) foram resistentes ao sulfametoxazol-trimetropina. Dos 6 isolados de Pseudomonas aeruginosa, 1 (16,6\%) foi resistente ao imipenem. Das 9 bactérias isoladas de Acinetobacter, 1 (11,1\%) foi resistente ao meropenem e $4(44,4 \%)$ resistentes ao imipenem. Em relação às 6 bactérias isoladas de Escherichia coli, 2 $(33,3 \%)$ foram resistentes ao antibiótico ciprofloxacina e $2(33,3 \%)$ ao ceftriaxona. 


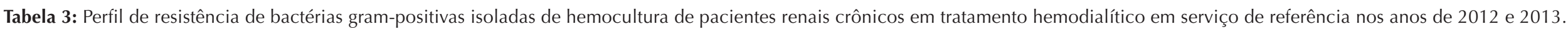

\begin{tabular}{|c|c|c|c|c|c|c|c|c|c|c|c|c|c|c|c|c|c|c|}
\hline$\underset{\text { (n) }}{\text { Microrganismo }}$ & $\begin{array}{l}\text { LEV } \\
\text { (n)\% }\end{array}$ & $\underset{\text { (n) } \%}{\text { CIP }}$ & $\begin{array}{l}\text { AMP } \\
\text { (n) \% }\end{array}$ & $\begin{array}{l}\text { OXA } \\
\text { (n) } \%\end{array}$ & $\begin{array}{l}\text { SUT } \\
\text { (n)\% }\end{array}$ & $\begin{array}{l}\text { CLI } \\
\text { (n) } \%\end{array}$ & $\begin{array}{l}\text { CEF } \\
\text { (n) } \%\end{array}$ & $\begin{array}{l}\text { PEN } \\
\text { (n)\% }\end{array}$ & VAN & $\begin{array}{l}\text { AMO } \\
(\mathbf{n}) \%\end{array}$ & $\begin{array}{l}\text { TET } \\
\text { (n)\% }\end{array}$ & $\begin{array}{l}\text { ERI } \\
(\mathbf{n}) \%\end{array}$ & $\begin{array}{l}\text { GEN } \\
\text { (n) } \%\end{array}$ & $\begin{array}{l}\text { AMI } \\
\text { (n)\% }\end{array}$ & $\begin{array}{l}\text { CEX } \\
(\mathbf{n}) \%\end{array}$ & $\begin{array}{l}\text { CET } \\
\text { (n)\% }\end{array}$ & $\begin{array}{l}\text { OFL } \\
(\mathbf{n}) \%\end{array}$ & $\begin{array}{l}\text { CEF } \\
\text { (n) } \%\end{array}$ \\
\hline $\begin{array}{l}\text { Staphylococcus } \\
\text { epidermidis (1) }\end{array}$ & - & - & - & - & - & - & - & - & - & - & - & - & - & - & - & - & - & - \\
\hline $\begin{array}{l}\text { Staphylococcus } \\
\text { sp. (8) }\end{array}$ & $\begin{array}{c}(5) \\
62,5\end{array}$ & $\begin{array}{c}(5) \\
62,5\end{array}$ & $\begin{array}{l}(8) \\
100\end{array}$ & $\begin{array}{c}(3) \\
37,5\end{array}$ & $\begin{array}{c}(3) \\
37,5\end{array}$ & $\begin{array}{l}(2) \\
25\end{array}$ & $\begin{array}{l}(4) \\
50\end{array}$ & $\begin{array}{c}(7) \\
87,5\end{array}$ & - & $\begin{array}{l}(4) \\
50\end{array}$ & $\begin{array}{l}(2) \\
25\end{array}$ & $\begin{array}{l}(4) \\
50\end{array}$ & $\begin{array}{c}(3) \\
37,5\end{array}$ & - & $\begin{array}{c}(1) \\
12,5\end{array}$ & - & - & - \\
\hline $\begin{array}{l}\text { Streptococcus do } \\
\text { grupo 'viridans' } \\
\text { (1) }\end{array}$ & $\begin{array}{l}(1) \\
100\end{array}$ & - & $\begin{array}{l}(1) \\
100\end{array}$ & - & - & $\begin{array}{l}(1) \\
100\end{array}$ & $\begin{array}{c}(1) \\
100\end{array}$ & $\begin{array}{l}(1) \\
100\end{array}$ & - & $\begin{array}{c}(1) \\
100\end{array}$ & - & $\begin{array}{l}(1) \\
100\end{array}$ & - & - & - & - & $\begin{array}{l}(1) \\
100\end{array}$ & $\begin{array}{l}(1) \\
100\end{array}$ \\
\hline $\begin{array}{l}\text { Enterococcus } \\
\text { sp. (2) }\end{array}$ & $\begin{array}{l}(1) \\
50\end{array}$ & $\begin{array}{l}(1) \\
50\end{array}$ & - & - & $\begin{array}{l}(2) \\
100\end{array}$ & - & $\begin{array}{l}(2) \\
100\end{array}$ & - & - & - & - & $\begin{array}{l}(1) \\
50\end{array}$ & $\begin{array}{c}(2) \\
100\end{array}$ & $\begin{array}{c}(2) \\
100\end{array}$ & - & $\begin{array}{l}(1) \\
50\end{array}$ & - & - \\
\hline $\begin{array}{l}\text { Streptococcus } \\
\text { agalactiae (1) }\end{array}$ & - & - & - & - & $\begin{array}{l}(1) \\
100\end{array}$ & - & - & - & - & - & $\begin{array}{l}(1) \\
100\end{array}$ & - & $\begin{array}{l}(1) \\
100\end{array}$ & $\begin{array}{l}(1) \\
100\end{array}$ & - & - & - & - \\
\hline $\begin{array}{l}\text { Streptococcus } \\
\text { sp. (1) }\end{array}$ & - & - & - & - & $\begin{array}{l}(1) \\
100\end{array}$ & - & - & - & - & - & - & - & $\begin{array}{l}(1) \\
100\end{array}$ & $\begin{array}{c}(1) \\
100\end{array}$ & - & - & - & - \\
\hline
\end{tabular}

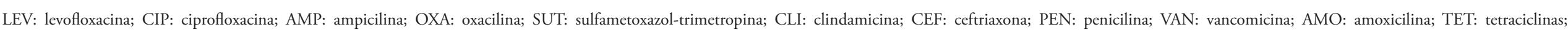
ERI: eritromicina; GEN: gentamicina; AMI: amicacina; CEX: cefoxitina; CET: ceftazidina; OFL: ofloxacina; CEF: cefepime.

Fonte: Elaborada pelos autores, 2014. 


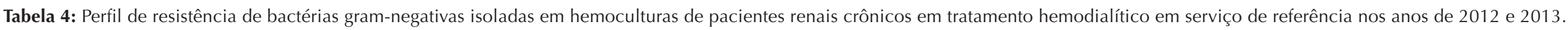

\begin{tabular}{|c|c|c|c|c|c|c|c|c|c|c|c|c|c|c|c|c|c|c|c|c|c|}
\hline $\begin{array}{l}\text { Microrganismo } \\
\text { (n) }\end{array}$ & $\begin{array}{l}\text { LEV } \\
\text { (n) } \%\end{array}$ & $\begin{array}{l}\text { CIP } \\
\text { (n) } \%\end{array}$ & $\begin{array}{l}\text { AMP } \\
(\mathbf{n}) \%\end{array}$ & $\begin{array}{l}\text { TOB } \\
\text { (n) } \%\end{array}$ & $\begin{array}{l}\text { SUT } \\
(\mathbf{n}) \%\end{array}$ & $\begin{array}{l}\text { CEF } \\
\text { (n) } \%\end{array}$ & $\begin{array}{l}\text { POL } \\
\text { (n)\% }\end{array}$ & $\begin{array}{l}\text { AMO } \\
(\mathbf{n}) \%\end{array}$ & $\begin{array}{l}\text { TET } \\
(\mathbf{n}) \%\end{array}$ & $\begin{array}{l}\text { TIC } \\
\text { (n)\% }\end{array}$ & $\begin{array}{l}\text { AZT } \\
\text { (n) } \%\end{array}$ & $\begin{array}{l}\text { CLO } \\
\text { (n) } \%\end{array}$ & $\begin{array}{l}\text { GEN } \\
\text { (n)\% }\end{array}$ & $\begin{array}{l}\text { MER } \\
\text { (n)\% }\end{array}$ & $\begin{array}{l}\text { AMI } \\
\text { (n)\% }\end{array}$ & $\begin{array}{l}\text { PIP } \\
(\mathbf{n}) \%\end{array}$ & $\begin{array}{l}\text { CEF } \\
(\mathbf{n}) \%\end{array}$ & $\begin{array}{l}\text { CET } \\
(\mathbf{n}) \%\end{array}$ & $\begin{array}{l}\text { CEF } \\
\text { (n) } \%\end{array}$ & $\begin{array}{l}\text { CEL } \\
(\mathbf{n}) \%\end{array}$ & $\begin{array}{l}\text { IMI } \\
\text { (n) } \%\end{array}$ \\
\hline $\begin{array}{l}\text { Escherichia } \\
\text { coli (6) }\end{array}$ & $\begin{array}{c}(2) \\
33,3\end{array}$ & $\begin{array}{c}(2) \\
33,3\end{array}$ & $\begin{array}{l}(3) \\
50\end{array}$ & - & $\begin{array}{l}(3) \\
50\end{array}$ & $\begin{array}{c}(2) \\
33,3\end{array}$ & - & $\begin{array}{c}(2) \\
33,3\end{array}$ & $\begin{array}{c}(2) \\
33,3\end{array}$ & - & - & - & - & - & - & - & $\begin{array}{c}(2) \\
33,3\end{array}$ & - & - & $\begin{array}{c}(2) \\
33,3\end{array}$ & - \\
\hline $\begin{array}{l}\text { Citrobacter } \\
\text { freundii (1) }\end{array}$ & - & - & $\begin{array}{l}(1) \\
100\end{array}$ & - & $\begin{array}{c}(1) \\
100\end{array}$ & - & - & $\begin{array}{c}(1) \\
100\end{array}$ & $\begin{array}{c}(1) \\
100\end{array}$ & - & - & - & - & - & - & - & $\begin{array}{l}(1) \\
100\end{array}$ & - & - & $\begin{array}{l}(1) \\
100\end{array}$ & - \\
\hline $\begin{array}{l}\text { Pseudomonas } \\
\text { aeruginosa (6) }\end{array}$ & - & - & - & $\begin{array}{c}(2) \\
33,3\end{array}$ & - & - & $\begin{array}{c}(2) \\
33,3\end{array}$ & - & - & $\begin{array}{l}(3) \\
50\end{array}$ & $\begin{array}{l}(3) \\
50\end{array}$ & - & $\begin{array}{c}(2) \\
33,3\end{array}$ & - & $\begin{array}{c}(1) \\
16,6\end{array}$ & $\begin{array}{c}(1) \\
16,6\end{array}$ & - & $\begin{array}{c}(1) \\
16,6\end{array}$ & - & - & $\begin{array}{c}(1) \\
16,6\end{array}$ \\
\hline $\begin{array}{l}\text { Pseudomonas } \\
\text { sp. (2) }\end{array}$ & - & - & - & - & - & - & - & - & - & $\begin{array}{l}(2) \\
100\end{array}$ & - & - & - & - & - & - & - & - & - & - & - \\
\hline $\begin{array}{l}\text { Acinetobacter } \\
\text { (9) }\end{array}$ & $\begin{array}{c}(1) \\
11,1\end{array}$ & $\begin{array}{c}(1) \\
11,1\end{array}$ & - & - & $\begin{array}{c}(3) \\
33,3\end{array}$ & $\begin{array}{c}(3) \\
33,3\end{array}$ & - & - & - & $\begin{array}{c}(1) \\
11,1\end{array}$ & $\begin{array}{c}(3) \\
33,3\end{array}$ & - & $\begin{array}{c}(3) \\
33,3\end{array}$ & $\begin{array}{c}(1) \\
11,1\end{array}$ & $\begin{array}{c}(2) \\
22,2\end{array}$ & $\begin{array}{c}(1) \\
11,1\end{array}$ & - & $\begin{array}{c}(3) \\
33,3\end{array}$ & $\begin{array}{c}(4) \\
44,4\end{array}$ & - & $\begin{array}{l}(4) \\
44,4\end{array}$ \\
\hline $\begin{array}{l}\text { Stenotrophomonas } \\
\text { maltophilia (8) }\end{array}$ & - & - & - & - & $\begin{array}{c}(3) \\
37,5\end{array}$ & $\begin{array}{l}(2) \\
25\end{array}$ & - & - & $\begin{array}{c}(3) \\
37,5\end{array}$ & $\begin{array}{l}(4) \\
50\end{array}$ & $\begin{array}{c}(1) \\
12,5\end{array}$ & $\begin{array}{c}(3) \\
37,5\end{array}$ & $\begin{array}{l}(6) \\
75\end{array}$ & - & $\begin{array}{l}(6) \\
75\end{array}$ & - & - & $\begin{array}{l}(4) \\
50\end{array}$ & $\begin{array}{l}(4) \\
50\end{array}$ & - & $\begin{array}{l}(6) \\
75\end{array}$ \\
\hline $\begin{array}{l}\text { Enterobacter } \\
\text { cloacae }(5)\end{array}$ & $\begin{array}{l}(1) \\
20\end{array}$ & $\begin{array}{l}(1) \\
20\end{array}$ & $\begin{array}{l}(3) \\
60\end{array}$ & - & $\begin{array}{l}(1) \\
20\end{array}$ & $\begin{array}{l}(1) \\
20\end{array}$ & - & $\begin{array}{l}(5) \\
100\end{array}$ & $\begin{array}{l}(1) \\
20\end{array}$ & - & - & - & $\begin{array}{l}(1) \\
20\end{array}$ & - & - & - & $\begin{array}{l}(5) \\
100\end{array}$ & $\begin{array}{l}(1) \\
20\end{array}$ & $\begin{array}{l}(1) \\
20\end{array}$ & $\begin{array}{l}(5) \\
100\end{array}$ & - \\
\hline $\begin{array}{l}\text { Morganella } \\
\text { morganii (1) }\end{array}$ & $\begin{array}{l}(1) \\
100\end{array}$ & $\begin{array}{l}(1) \\
100\end{array}$ & $\begin{array}{l}(1) \\
100\end{array}$ & - & - & - & - & $\begin{array}{l}(1) \\
100\end{array}$ & $\begin{array}{c}(1) \\
100\end{array}$ & - & - & - & - & - & - & - & - & - & - & $\begin{array}{l}(1) \\
100\end{array}$ & - \\
\hline $\begin{array}{l}\text { Bacillus } \\
\operatorname{sp}(1)\end{array}$ & - & - & - & - & - & - & - & - & - & - & - & - & - & - & - & - & - & - & - & - & - \\
\hline $\begin{array}{l}\text { Bastonetes } \\
\text { gram-negativos (2) }\end{array}$ & $\begin{array}{l}(1) \\
50\end{array}$ & $\begin{array}{l}(1) \\
50\end{array}$ & $\begin{array}{l}(1) \\
50\end{array}$ & - & - & $\begin{array}{c}(2) \\
100\end{array}$ & - & $\begin{array}{l}(1) \\
50\end{array}$ & $\begin{array}{c}(2) \\
100\end{array}$ & - & $\begin{array}{l}(1) \\
50\end{array}$ & - & $\begin{array}{l}(2) \\
100\end{array}$ & - & $\begin{array}{l}(2) \\
100\end{array}$ & - & $\begin{array}{l}(1) \\
50\end{array}$ & $\begin{array}{l}(2) \\
100\end{array}$ & $\begin{array}{c}(2) \\
100\end{array}$ & $\begin{array}{l}(1) \\
50\end{array}$ & $\begin{array}{l}(2) \\
100\end{array}$ \\
\hline
\end{tabular}

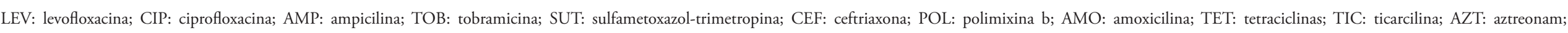
CLO: clorafenicol; GEN: gentamicina; MER:meropenem; AMI: amicacina; PIP: piperacilina; CEF: cefoxitina; CET: ceftazidina; CEF: cefepime; CEL: cefalotina; IMI: imipenem.

Fonte: Elaborada pelos autores, 2014. 


\section{Discussão}

A Anvisa distingue dois grupos de infecções de corrente sanguínea: as que podem ser identificadas por hemocultura positiva e, as identificáveis por critérios clínicos, e considera que a primeira tem critério diagnóstico mais fidedigno ${ }^{11}$. Segundo informaçóes do laboratório, a coleta de sangue foi realizada conforme critérios preconizados pela Anvisa, em dois sítios diferentes e após rigorosa antissepsia. Isso é importante para evitar o isolamento de bactérias colonizantes da pele e possibilita mais segurança na interpretação do resultado da cultura.

Neste estudo se observou uma média de incidência de infecçóes da corrente sanguínea de 2,45. Há fatores de risco para o desenvolvimento da infecção de corrente sanguínea, relacionados ao paciente, tais como: a hipertensão, o diabetes mellitus e a hipoalbuminemia ${ }^{7}$, também presentes na amostra deste estudo.

Em pesquisa abrangendo 156 nefropatas crônicos em uso de cateter venoso central durante um ano, houve elevada incidência de infecção de corrente sanguínea $(61 \%)$. A bacteremia em pacientes em hemodiálise progride rapidamente, e a cura é mais lenta para esses indivíduos do que para os náo urêmicos. Isso pode estar relacionado com alteraçóes imunológicas, tais como deficiência na imunidade celular por deficiência de aminoácidos; deficiência de vitaminas $\mathrm{B}, \mathrm{C}, \mathrm{D}, \mathrm{E}$ e zinco; aumento da atividade supressora celular; anorexia por retenção de produtos nitrogenados; e anemia significativa secundária à deficiência de eritropoietina ${ }^{12}$.

Neste estudo, o sexo masculino foi identificado como maioria em tratamento de hemodiálise. Resultado parecido também foi encontrado em outra pesquisa em que $60 \%$ dos entrevistados eram homens ${ }^{5}$. Esse fato pode ser explicado devido às dificuldades de adesão e participação masculina aos cuidados da atenção primária à saúde, em prevenção de agravos ou em açóes de promoção. $\mathrm{O}$ que demonstra que os homens procuram o serviço de saúde somente quando precisam de algo imediatista ${ }^{13}$. Assim, é possível que a descoberta da doença aconteça com um diagnóstico já avançado, dificultando um prognóstico menos sombrio.

Observa-se que, neste estudo, a maioria dos pacientes tinha idade superior a 60 anos, o que corrobora com os resultados obtidos em outro estudo ${ }^{14}$. Pacientes com idade avançada costumam ser mais debilitados imunologicamente e apresentam mais doenças crônicas, tornando-se suscetíveis às infecçóes hospitalares. Além do fator idade, os dados deste estudo mostram que o diagnóstico de base que antecedeu à insuficiência renal também é compatível com a literatura que destaca o diabetes mellitus e a nefropatia hipertensiva como as causas mais frequentes desse agravo ${ }^{15}$.
Seguindo critérios da Anvisa, das 152 hemoculturas realizadas, $58,9 \%$ apresentaram resultados positivos. Essa elevada positividade pode estar relacionada às características dos pacientes pesquisados, os quais são na maioria portadores de outras doenças crônicas e apresentam sistema imunológico deficitário. Pode ainda estar relacionada: ao tipo de cateter, à habilidade técnica do profissional, às internaçóes em centros de terapias intensivas, ao tempo de permanência do cateter, ao local de inserção do cateter (veia femoral) manipulaçôes excessivas e/ou inadequadas, entre outros.

No cômputo geral das medidas de prevenção e controle da infecção nos serviços de diálise, tem sido amplamente enfatizado o rigor nos princípios básicos de assepsia: a higienizaçáo das mãos, o manuseio de material esterilizado, o processamento de artigos, o uso de equipamento de proteção individual, entre outros que atendam à manutenção da segurança biológica ${ }^{16}$.

Neste estudo, o principal grupo de bactérias isolado de hemoculturas foi o das gram-negativas $(55,4 \%)$, revelando que estas vêm se sobressaindo às gram-positivas $(44,5 \%)$ como agente de infecção de corrente sanguínea. Este estudo corrobora com o estudo em que foram acompanhados 65 pacientes em hemodiálise em uso de cateter e que constatou que as bactérias gram-negativas nesses pacientes foram as mais prevalentes $(75 \%)^{17}$. Estudos trazem que a mortalidade associada a bacteremias por bastonetes gram-negativos é maior quando comparada à associada aos cocos gram-positivos ${ }^{17,18}$.

Nesta investigação, Stenotrophomonas maltophilia, Acinetobacter e Pseudomonas aeruginosa foram os bacilos gram-negativos não fermentadores mais prevalentes entre os isolados de hemoculturas. Esse dado é preocupante, tendo-se em vista que infecçóes causadas por esses microrganismos são de difícil tratamento, devido à elevada resistência aos antimicrobianos ${ }^{19,20}$.

Em relação aos gram-positivos o Staphylococcus aureus foi o microrganismo mais isolado nas hemoculturas. Pacientes hospitalizados com infecção por $S$. aureus têm risco cinco vezes maior de mortalidade, em uma comparação com infecção por outros microrganismos gram-positivos. A mortalidade associada com bacteremia, causada por Staphylococcus aureus, varia de 11,9\% a $46,5 \%$ ao ano. Estudos mostram que infecçôes de corrente sanguínea associadas a esse agente podem levar a graves infecçóes, tais como sepse, endocardite e endoftalmite ${ }^{12,21}$.

De acordo com os critérios de definição de bactérias multirresistentes sob vigilância no hospital pesquisado, o estudo demonstrou a existência de 74 tipos de microrganismos identificados nas hemoculturas, sendo que $11(14,8 \%)$ tinham perfil de multirresistência. A ocorrência das infecçóes causadas por microrganismos multirresistentes constitui um problema mundial de 
saúde pública. Bactérias resistentes tornam-se cada vez mais comuns nas instituiçóes de cuidado em saúde e estấo associadas aos altos índices de mortalidade e morbidade, o que faz aumentar consideravelmente os custos para atendimento hospitalar ${ }^{21,22}$.

Neste estudo foi observada uma resistência superior a $50 \%$ dos microrganismos aos antimicrobianos testados, sendo que $5,2 \% \operatorname{dos} S$. aureus foram resistentes à oxacilina. Dentre os bacilos gram-negativos náo fermentadores, o P. aeruginosa teve $16,6 \%$ de resistência ao imipenem. O Stenotrophomonas maltophilia apresentou um perfil de alta resistência: 37,7\% dos microrganismos foram resistentes ao sulfametoxazol-trimetropina. Quanto ao Acinetobacter, houve $11,1 \%$ de resistência ao meropenem e $44,4 \%$ ao imipenem. E no que se refere ao Escherichia coli, a resistência foi de 33,3\% ao ciprofloxacina e ao ceftriaxona.

A literatura estabelece que é importante que cada unidade de hemodiálise mantenha um banco de dados de todas as infecçóes de correntes sanguíneas suspeitas e comprovadas contendo: os episódios de bacteremias e fungemias; os microrganismos causadores dessas infecçôes; o perfil de susceptibilidade antimicrobiana; e o sítio potencial de infecção (cateter, pneumonia, trato urinário etc.). Isso porque esses resultados permitem nortear a terapêutica inicial ${ }^{9,12,17,18}$.

Tendo em vista que essa pesquisa considerou apenas as infecçóes laboratorialmente confirmadas, devido à falta de registros completos dos critérios clínicos, a incidência de infecçôes poderia ser superior à encontrada nesta pesquisa, constatando assim um viés do estudo.

\section{Conclusão}

Pode-se concluir que a incidência de infecção por bactérias multirresistentes é alta e tem como destaque o Staphylococcus aureus, Escherichia coli, Pseudomonas aeruginosa, Acinetobacter e Stenotrophomonas maltophilia no local de estudo. O isolamento dessas bactérias multirresistentes é preocupante, haja vista as limitaçóes de opções terapêuticas e aumento da letalidade.

Acrescenta-se a isso que por se tratar de uma população com alto risco de infecção, na presença de microrganismos multirresistentes na corrente sanguínea, deve-se desencadear medidas adicionais de prevenção de transmissão, evitando assim, a ocorrência de um surto entre esta população.

Destaca-se ainda que a redução das infecções da corrente sanguínea é possível quando um conjunto de medidas de prevenção é aplicado adequadamente. Dessa forma, toda equipe de saúde deve ser orientada e capacitada constantemente sobre a importância da prevenção e do controle das infecções hospitalares, de forma a prestar uma assistência de qualidade aos usuários.

\section{Referências}

1. Jha V, Garcia-Garcia G, Iseki K, Li Z, Naicker S, Plattner $\mathrm{B}$, et al. Chronic kidney disease: global dimension and perspectives. Lancet. 2013;382(9888):260-72.

2. Santos BP, Oliveira VA, Soares MC, Schwartz E. Doença renal e relaçáo com a hemodiálise. ABCS Health Sci. 2017;42(1):8-14.

3. Sociedade Brasileira de Nefrologia. Hemodiálise [Internet]. 2017 [citado em 2017 set 17]. Disponível em: https://goo.gl/EpUYxa

4. Menezes FG, Barreto DV, Abreu RM, Roveda F, Pecoits Filho RFS. Panorama do tratamento hemodialítico financiado pelo Sistema Único de Saúde: uma perspectiva econômica. J Bras Nefrol. 2015; 37(3):367-78.

5. Ribeiro LC, Arreguy-Sena C, Souza LC, Oliveira DV. Significados atribuídos à fístula arteriovenosa pela pessoa em hemodiálise. HU Rev. 2013;39(1-2):45-52.

6. Danski MTR, Pontes L, Schwanke AA, Lind J. Infecção da corrente sanguínea relacionada a cateter venoso central para hemodiálise: revisão integrativa. Rev Baiana Enferm. 2017; 31(1):1-10.

7. Brasil. Agência Nacional de Vigilância Sanitária. Critérios diagnósticos de infecção relacionada à assistência à saúde [Internet]. 2a ed. Brasília, DF; 2017 [citado em 2017 set 17]. Disponível em: https://goo.gl/cD4aQs

8. Fram DS, Taminato M, Ferreira D, Neves L, Belasco AG, Barbosa DA. Prevention of catheter-related bloodstream infections in patients on hemodialysis. Acta Paul Enferm. 2009; 22(Spec 1):564-8.

9. Rosado V, Romanelli RMC, Camargos PAM. Risk factors and preventive measures for catheter-related bloodstream infections. J Pediatr (Rio J). 2011;87(6):469-77.

10. Rossi F, Andreazzi DB. Resistência bacteriana: interpretando o antibiograma. São Paulo: Atheneu; 2005.

11. Brasil. Agência Nacional de Vigilância Sanitária. Corrente sanguínea: critérios nacionais de infecçóes relacionados à assistência à saúde [Internet]. [S.1.]; 2009 [citado em 2017 set 17]. Disponível em: https://goo.gl/t8GHvY

12. Grothe C, Belasco AGS, Bittencourt ARC, Vianna LA, Sesso RCC, Barbosa DA. Incidence of bloodstream infection among patients on hemodialysis by central venous catheter. Rev Lat Am Enfermagem. 2010;18(1):73-80.

13. Solano LC, Bezerra MAC, Medeiros RS, Carlos EF, Carvalho FP, Miranda FAN. O acesso do homem ao serviço de saúde na atenção primária. Rev Pesqui Cuid Fundam (Online). 2017;9(2):302-8.

14. Izaias EM, Dellaroza MSG, Rossaneis MA, Belei RA. Custo e caracterização de infecção hospitalar em idosos. Ciênc Saúde Coletiva. 2014;19(8):3395-402.

15. Sesso RCC, Lopes AA, Thomé FS, Lugon JR, Watanabe Y, Santos DR. Diálise crônica no Brasil: relatório do Censo Brasileiro de Diálise, 2011. J Bras Nefrol. 2012;34(3):272-7. 
16. Henrique DM, Tadeu CN, Alves FH, Trindade LPC, Fernandes MSR, Macedo ML, et al. Fatores de risco e recomendaçôes atuais para prevenção de infecção associada a cateteres venosos centrais: uma revisão de literatura. Rev Epidemiol Control Infect. 2013;3(4):134-8

17. Bevilacqua JL, Gomes JG, Santos VFB, Canziani MEF. Comparação entre citrato trissódico e heparina como soluçáo para selo de cateter em pacientes em hemodiálise. J Bras Nefrol. 2011;33(1):86-92.

18. Leão LSNO, Passos XS, Reis C, Valadão LMA, Silva MRR, Pimenta FC. Fenotipagem de bactérias isoladas em hemoculturas de pacientes críticos. Rev Soc Bras Med Trop. 2007;40(5):537-40.

19. Machado GM, Lago A, Fuentefria SRR, Fuentefria DB. Ocurrence and the susceptibility to antimicrobial agents in Pseudomonas aeruginosa and Acinetobacter sp. at a tertiary hospital in southern Brazil. Rev Soc Bras Med Trop 2011;44:168-72.

20. Rodrigues LS, Gioia TSRD, Rossi F. Stenotrophomonas maltophilia: resistência emergente ao SMX-TMP em isolados brasileiros. uma realidade? J Bras Patol Med Lab. 2011;47(5):511-7.

21. Esmanhoto CG, Taminato M, Fram DS, Belasco AGS, Barbosa DA. Microrganismos isolados de pacientes em hemodiálise por cateter venoso central e evolução clínica relacionada. Acta Paul Enferm. 2013;26(5):413-20.

22. Naves KSC, Trindade NV, Gontijo Filho PP. Methicillinresistant Staphylococcus aureus bloodstream infection: risk factors and clinical outcome in non-intensive-care units. Rev Soc Bras Med Trop. 2012;45(2):189-93.

\section{Como citar este artigo:}

Paiva PA, Paula BP, Santos MFF, Silveira BRM. Incidência de infecçôes da corrente sanguínea em pacientes nefropatas. Rev. Aten. Saúde. 2018;16(55):72-80. 